\title{
CONSEJO DE ADMINISTRACIÓN DEFICITARIO, CONSEJO DE ADMINISTRACIÓN INCOMPLETO Y VALIDEZ DE LA CONVOCATORIA DE LA JUNTA GENERAL DE SOCIOS
}

(A propósito de la Sentencia del Tribunal Supremo de 16 de enero de 2019)

Francisco J. Alonso Espinosa

Catedrático de Derecho Mercantil 


\section{Preliminar}

La STS (Sala $1^{\mathrm{a}}$ ) de 16 de enero de 2019 (Rec. 81/2016; ponente: Pedro José Vela Torres) resuelve sobre los criterios de estimación como causas de impugnación de la validez de los acuerdos de la junta general de socios relativas a: (i) la convocatoria de la junta general por acuerdo de un consejo de administración de tres miembros pero constituido solamente por dos consejeros a causa de la previa dimisión del ex-consejero y también socio impugnante, y (ii) la lesión del derecho de información del mismo socio y ex-administrador antes y durante la celebración de la junta general. Nos ocupamos aquí del primero de los problemas relativo a la convocatoria de la junta general por consejo de administración incompleto como causa de impugnación de la junta general y de sus acuerdos.

El supuesto de hecho objeto de resolución es relativo a un consejo de administración que, según los estatutos sociales, ha de estar formado por tres consejeros pero que, al tiempo de ser adoptado el acuerdo de convocatoria de la junta general de socios, había quedado reducido a dos consejeros a causa de la previa dimisión del ex-consejero y socio impugnante. Éste alega la nulidad de la junta y sus acuerdos a causa de la nulidad del acto de convocatoria de la junta general por proceder ésta de un consejo de administración formado solamente por dos consejeros que, según el recurrente, carecería, por ello, de la capacidad de adoptar acuerdos válidos.

El recurrente formula tal alegación sobre la base del art. 242.1 LSC -según el cual “El consejo de administración estará formado por un mínimo de tres miembros"- presuponiendo que si, como es el caso del supuesto, el consejo de administración ya no responde a tal exigencia de "número mínimo de tres miembros" al haber quedado con sólo dos a causa de la previa dimisión del propio recurrente, el consejo queda como "bloqueado" o desprovisto de su capacidad para ejercer las competencias que le son propias hasta tanto no sea regularizada su composición. Implícitamente, tal razonamiento conduce a la afirmación según la cual la única solución posible a tal situación consiste en que los administradores que permanecen en su cargo convocasen la junta o, en su caso, algún socio instase la convocatoria de la junta general por parte del Letrado de la Administración de Justicia o bien por parte del Registrador mercantil, como única vía para lograr el supuesto "desbloqueo" del consejo mediante el nombramiento de un consejero sustituto (cf. art. 171 LSC; ello a salvo el caso de que hubiera sido nombrado algún consejero suplente, cf. arts. 216 LSC y 147.2 RRM). Según esta posición, tratándose de una SA (como es el caso del supuesto), ni tan siquiera podría acudirse al nombramiento del sustituto del consejero dimisionario por el sistema de cooptación (cf. art. 244 LSC) ya que el consejo quedaría igualmente "bloqueado" a tal efecto. En conclusión, según esta interpretación rígida del art. 242.1 LSC -rígida por estar basada exclusivamente en la literalidad del precepto (cf. art. $3^{\circ} \mathrm{CC}$ )- defendida por el recurrente como causa de nulidad de la convocatoria de la junta general, se seguiría la siguiente situación jurídica intolerable por absurda: la actividad de la sociedad podría quedar prácticamente paralizada (a salvo la posibilidad de actuación de posibles consejeros delegados o apoderados más o menos generales) hasta tanto la junta general que convocase el Letrado de la Administración de Justicia o bien el Registrador mercantil, no decidiese sobre la recomposición del consejo de administración dotándolo de, al menos, tres miembros. 


\section{Consejo de administración deficitario vs. consejo de administración meramente incompleto}

La Sala resuelve esta parte de la litis mediante el recurso a la interpretación sistemática de los arts. 171, 242 y 247.2 LSC y mediante adopción como propia de la doctrina de la DGRN formulada al respecto en Resolución de 14 de marzo de 2016 (BOE de 6 de abril de 2016). El núcleo de esta doctrina reside en la distinción entre dos supuestos de consejo de administración "anómalo" bien diferenciados y de muy diferente trascendencia jurídica cada uno: el consejo de administración deficitario y el consejo de administración meramente incompleto.

(i) Un consejo de administración es deficitario cuando, por las circunstancias que sean (muerte, dimisión, destitución de administradores, caducidad del cargo, entre otras), el consejo ha quedado desprovisto de miembros suficientes para poder constituirse regularmente, esto es, para alcanzar el quórum de constitución exigido por la Ley (cf. art. 247 LSC) o, en su caso, por los estatutos sociales. Si atendemos al criterio legal presente en el art. 247 LSC, un consejo de administración sería deficitario cuando haya perdido la mitad o más de sus miembros. Un consejo de administración en tales circunstancias no podrá constituirse válidamente ya que resulta imposible la reunión de la mayoría de sus miembros según exige el art. 247 LSC.

(ii) Supuesto distinto es el del consejo meramente incompleto. Este supuesto tiene lugar en los casos en que el consejo de administración ha perdido a alguno o algunos de sus miembros pero sin que tal pérdida impida que el consejo pueda ser válidamente constituido ya que el número de miembros que conserva representa la mayoría de su total.
Por tanto, un consejo de administración deficitario no puede funcionar ni adoptar acuerdos válidos ya que no puede reunirse válidamente al no poder cumplir con el requisito de reunión del quórum de constitución legal o estatutariamente establecido. En cambio, un consejo de administración meramente incompleto sí puede reunirse y adoptar acuerdos válidos ya que su mero carácter incompleto no le impide alcanzar la reunión del quórum de constitución establecido por la Ley.

Pues bien, si trasladamos esta distinción entre consejo deficitario y consejo incompleto al caso del supuesto de hecho de la litis objeto de la STS de 16 de enero de 2019 -consistente en un consejo de administración formado por tres miembros que ha perdido a uno de ellos por dimisión- resulta que nos hallamos ante el supuesto de consejo meramente incompleto porque conserva la mayoría de sus miembros -los dos restantes consejeros de los tres que lo forman- de forma que ambos consejeros pueden reunirse válidamente -pueden constituirse como consejo- y adoptar acuerdos como consejo de administración, si bien en este singular supuesto del consejo compuesto por sólo tres miembros, deben, obviamente, adoptarlos por unanimidad de ambos en el caso de la SA (cf. art. 248.1 LSC) o bien mediante la abstención de uno y el voto a favor del otro consejero en el caso de la SRL (salvo que los estatutos sociales de la SRL exijan mayoría absoluta de concurrentes u otra mayoría más cualificada, cf. art. 245.1 LSC).

\section{Los arts. 171 LSC y 141 RRM como criterios de interpretación sistemática}

Como hemos observado, la Sala también trae a colación el art. 171 LSC para fundamentar el fallo. Se trata de un precepto cuya consideración permite reforzar la fundamentación jurídica ya 
expuesta aunque su objeto carezca de relación directa con el problema objeto de la litis. El art. 171 LSC contiene dos medidas anti-parálisis de la actividad social ante los supuestos de órgano de administración deficitario, esto es, ante los casos de "muerte o de cese del administrador único, de todos los administradores solidarios, de alguno de los administradores mancomunados, o de la mayoría de los miembros del consejo de administración, sin que existan suplentes":

(i) En primer lugar, se atribuye a favor de cualquier socio la facultad de solicitar del Letrado de la Administración de Justicia o del Registrador mercantil del domicilio social la convocatoria de junta general al exclusivo objeto de que la misma acuerde, en su caso, el nombramiento de los administradores necesarios en función de regularizar el órgano deficitario. (ii) En segundo lugar, se atribuye a favor de cualquiera de los administradores que permanezcan en el ejercicio del cargo la facultad de convocar por sí mismos y de forma directa la junta general, también con el único objeto de regularizar el órgano de administración deficitario mediante el acuerdo de nombramiento de los administradores necesarios según la modalidad órgano de administración de que se trate.

En este sentido, la Sala refrenda la referida doctrina de la DGRN sobre el significado del art. 171 LSC (R. 14 de marzo de 2016, BOE 6 de abril) en el aspecto relativo al supuesto de "cese de la mayoría de los miembros del consejo de administración" (sin que existan suplentes). La facultad reconocida a favor de cualquier socio para solicitar la convocatoria de la junta general por el Letrado de la Administración de Justicia o bien por el Registrador mercantil, o bien la atribuida a favor de cualquier administrador que permanezca en el ejercicio del cargo para convocarla motu proprio y de forma directa, confirma, según la Sala, “que, en caso de cese de la mayoría, el consejo no puede constituirse válidamente (como demuestra la equiparación que hace el propio precepto a la imposibilidad de funcionamiento de las otras formas de organizar la administración). Lo que no sucede si el cese no ha afectado a la mayoría de los consejeros... La habilitación que el art. 171 LSC confiere a cualquiera de los administradores que permanecen en el cargo para convocar la junta general cuando se produce alguno de los cuatro supuestos especiales que prevé... implica que, en el resto de casos, el consejo puede constituirse válidamente y adoptar todo tipo de acuerdos. Es decir, al no tratarse de un consejo deficitario, que queda paralizado por el cese de la mayoría de sus vocales, sino mayoritario, por aplicación de la regla de la mayoría consagrada en el citado art. 247.2 LSC, puede seguir en funcionamiento mientras se provee a la cobertura de la vacante".

Aplicada tal doctrina al caso del consejo de administración compuesto por tres consejeros, la conclusión es que tal consejo puede quedar válidamente constituido con el acuerdo de dos de ellos [pues] no se da el supuesto de hecho previsto en el art. 171 LSC. Por lo que el consejo así constituido tiene competencia plena para convocar la junta general y para fijar el orden del día.

La Sala trae también a colación el art. 141 RRM según el cual, en caso de consejo de administración, basta que acepten la mayoría de los componentes designados para que el órgano quede válidamente constituido, sobre cuya base termina de apostillar la doctrina que sustenta el fallo (ver fundamentos jurídicos números 3 y 4). 